\title{
Study on Fluorescence Spectra of Thiamine and Riboflavin
}

\author{
Hui YANG ${ }^{1, a}$, Xue XIAO ${ }^{2}$, Xue Song $Z_{H A O}^{2}$, Lan $\mathrm{HU}^{1}$, Xian Feng XUE ${ }^{1}$ and Jie Song YE ${ }^{1}$ \\ ${ }^{1}$ New Star Application Technology Institute, Hefei, Anhui, 230031, China; \\ ${ }^{2}$ Key Lab. of Environmental Optics \& Technology, AlOFM, CAS, Hefei, Anhui, 230031, China
}

\begin{abstract}
This paper presents the intrinsic fluorescence characteristics of vitamin B1 and vitamin B2 with 3D fluorescence Spectrophotometer. Three strong fluorescence areas of vitamin B2 locate at $\lambda \mathrm{ex} / \lambda \mathrm{em}=270 / 525 \mathrm{~nm}$, $370 / 525 \mathrm{~nm}$ and $450 / 525 \mathrm{~nm}$ and one fluorescence areas of vitamin B1 locates at $\lambda \mathrm{ex} / \lambda \mathrm{em}=370 / 460 \mathrm{~nm}$ were found. The influence of $\mathrm{pH}$ of solution are also discussed, and with the PARAFAC algorithm, 9 vitamin $\mathrm{B} 2$ and vitamin $\mathrm{B} 1$ mixed solutions are successfully decomposed, and the emission profiles, excitation profiles, central wavelengths and the concentration of the two components were retrieved precisely through about 10 iteration times.
\end{abstract}

\section{Introduction}

The fluorescence of a folded protein or bio-aerosol is a mixture of the fluorescence from individual aromatic component and coenzyme. Riboflavin, known as vitamin $\mathrm{B} 2$, is an easily absorbed micronutrient with a key role in maintaining health in humans and animals. As such, vitamin B2 is required for a wide variety of cellular processes. Vitamin B2 plays a key role in energy metabolism, and is required for the metabolism of fats, ketone bodies, carbohydrates, and proteins ${ }^{[1]}$. Thiamine, known as vitamin $\mathrm{B} 1$, is one of $8 \mathrm{~B}$ vitamins, is used in many different body functions and deficiencies may have far reaching effects on the body, yet very little of this vitamin is stored in the body, and depletion of this vitamin can happen within 14 days. B vitamins are water-soluble and of great importance for the health of people, they can not be synthesized within the body, but be obtained from daily food, so the content measurement of B vitamins in the food is necessary for food security and research.

PARAFAC, a three way-decomposition method, has been found to be very useful in identifying the independent spectra of different types of fluorophores ${ }^{[2]}$. Compared to its predecessor, Principal Component Analysis (PCA) technique, PARAFAC provides both a quantitative and qualitative model of the data and separates the complex signal measured into its individual underlying fluorescent phenomena with specific excitation and emission spectra. It can track even small variations in EEM datasets by separating several independent groups of fluorophores from the overlapped components with a high resolution, so it is commonly used technique to monitor the mixed fluorescence EEMs. On the other hand, the weakness of PARAFAC model may include the assumption of the independence among the estimated components in the model, and potential inclusion of one or more poorly estimated components, which may significantly affect the spectra and scores of all other components ${ }^{[3]}$.

Some previous studies reported that PARAFAC was applied to resolve the mixed and overlapped spectra of vitamin B1, B2 and B6 ${ }^{[4]}$, accordingly, in this paper, discussed not only the fluorescence spectra of riboflavin and thiamine individually, but also the overlap of fluorescence spectra of vitamin $\mathrm{B} 1$ and vitamin $\mathrm{B} 2$ at the $\mathrm{Ex} / \mathrm{Em}$ area with wavelength of $300 \sim 550 / 370 \sim 610 \mathrm{~nm}$, by means of Parallel factor analysis (PARAFAC) method.

\section{Experimental Section}

\section{1 instruments and reagents}

The Molecular $\Sigma \mathrm{H}_{2} \mathrm{O}$ ultra pure water machine (Shanghai Molecular Co. Ltd) was used to generate the ultra purified water, UPW whose $\mathrm{pH}$ value is 5.4. The vitamin B2 mother liquid were compounded with Riboflavin from Amresco co.Ltd whose purity greater than or equal to $98 \%$, and the vitamin B1 from Sigma co.Ltd with purity greater than or equal to $99 \%$. All reagents and materials were weighed with Mettler Toledo precise electronic balance, and dissolved with Briton Robson Buffer with different $\mathrm{pH}$ values $(1.95,5.4,5.66,8.0$ and 11.92$)$.

\footnotetext{
${ }^{\mathrm{a}}$ Hui YANG :sanpedroman@163.com
} 
The solvents used in the experiments include $0.2 \mathrm{~mol} / \mathrm{L}$ $\mathrm{Na}_{2} \mathrm{HPO}_{4}$ buffer, $0.1 \mathrm{~mol} / \mathrm{L} \mathrm{C}_{6} \mathrm{H}_{8} \mathrm{O}_{7} \cdot \mathrm{H}_{2} \mathrm{O}$ buffer, $\mathrm{Na}_{2} \mathrm{HPO}_{4}$ and $\mathrm{C}_{6} \mathrm{H}_{8} \mathrm{O}_{7} \cdot \mathrm{H}_{2} \mathrm{O}$ mixed buffer, $1 \% \mathrm{~K}_{3}\left[\mathrm{Fe}(\mathrm{CN})_{6}\right]$ buffer, $2 \mathrm{~mol} / \mathrm{L} \mathrm{NaOH}$ buffer and $3 \mathrm{~mol} / \mathrm{L} \mathrm{H}_{2} \mathrm{SO}_{4}$ buffer. $0.2 \mathrm{~mol} / \mathrm{L}$ $\mathrm{Na}_{2} \mathrm{HPO}_{4}$ buffer was compounded by putting $28.4 \mathrm{~g}$ sodium phosphte dibasic anhydrous $\left(\mathrm{Na}_{2} \mathrm{HPO}_{4}\right.$, Tianjin guangfu chemical research institute, China) into $1000 \mathrm{~mL}$ UPW. $0.1 \mathrm{~mol} / \mathrm{L} \mathrm{C}_{6} \mathrm{H}_{8} \mathrm{O}_{7} \cdot \mathrm{H}_{2} \mathrm{O}$ buffer was compounded by put 21.01g citric acid monohydrate $\left(\mathrm{C}_{6} \mathrm{H}_{8} \mathrm{O}_{7} \cdot \mathrm{H}_{2} \mathrm{O}\right.$, Sinopharm Chemical Reagent Co.Ltd) into $1000 \mathrm{~mL}$ UPW. $\mathrm{Na}_{2} \mathrm{HPO}_{4}$ and $\mathrm{C}_{6} \mathrm{H}_{8} \mathrm{O}_{7} \cdot \mathrm{H}_{2} \mathrm{O}$ mixed buffer was compounded by mixing $0.2 \mathrm{~mol} / \mathrm{L} \quad \mathrm{Na}_{2} \mathrm{HPO}_{4}$ buffer and $\mathrm{C}_{6} \mathrm{H}_{8} \mathrm{O}_{7} \cdot \mathrm{H}_{2} \mathrm{O}$ buffer at the ration of $6: 1 ; 1 \% \mathrm{~K}_{3}\left[\mathrm{Fe}(\mathrm{CN})_{6}\right]$ buffer was compounded by put $1 \mathrm{~g}$ Potassium hexacyanoferrate buffer(Tianjin guangfu chemical research institute) into $100 \mathrm{~mL} \mathrm{UPW}$, and was diluted by mixing with $3 \mathrm{~mL}$ $2 \mathrm{~mol} / \mathrm{L} \mathrm{NaOH}$ buffer to $10 \mathrm{~mL}$.

The vitamin B2 and B1 mother liquid concentration are $10 \mathrm{mg} / \mathrm{L}$ respectively. The vitamin $\mathrm{B} 2$ and vitamin $\mathrm{B} 1$ mother reagent solutions were transferred through DragonLab whole disinfection manual single channel adjustable liquid shifter and dilute to working solutions of different concentrations. All reagents were of analytical grade, all solutions and put in amber glass bottles and stored in a refrigerator $\left(4{ }^{\circ} \mathrm{C}\right)$ because of the light sensitivity of vitamin B2.

3D fluorescence intensity measurements were carried out on an F-7000 FL spectrophotometer (Hitachi HighTechnologies Corporation, Japan).

\section{2 instrument settings and experiment procedure}

500ul Briton Robson Buffers with different $\mathrm{pH}$ values and mother liquids of different volumes were injected into the $10 \mathrm{ml}$ test tubes, and diluted with purified water to form the working liquids and background liquids.

For the fluorescence EEM measurements of vitamin B2, the spectrophotometer excitation wavelength ranged from $200.0 \mathrm{~nm}$, to $550.0 \mathrm{~nm}$, emission wavelength ranged from $450.0 \mathrm{~nm}$ to $650.0 \mathrm{~nm}$, scan speed was set at $12000 \mathrm{~nm} / \mathrm{min}$ with excitation and emission sampling interval of $10.0 \mathrm{~nm}$, excitation and emission slit of $5.0 \mathrm{~nm}$, the PMT voltage was set at $700 \mathrm{~V}$. Accordingly, for fluorescence EEM of thiamine, the excitation wavelength ranged from $300.0 \mathrm{~nm}$, to $400.0 \mathrm{~nm}$, emission wavelength ranged from $350.0 \mathrm{~nm}$ to $550.0 \mathrm{~nm}$. All experiments were performed at room temperature at $25^{\circ} \mathrm{C}$.

The 1st level and 2nd level Rayleigh scattering, Raman scattering and other background components within the fluorescence signals were corrected for the following analysis.

\subsection{Multi-components discrimination using PARAFAC method}

Based on the tri-linear decomposition theory, the parallel factor analysis(PARAFAC) method is a kind of mathematical model implemented through alternating least squares algorithm, which is widely applied to analyze three-dimensional or multi-dimensional data, to decompose $N$-dimensional data to the $N$ load matrixes.

The measured fluorescence spectrum EEM data is a $I \times J \times K$ matrix, in which, $I$ indicates the number of the samples, while $J$ and $K$ are the number of excitation wavelengths and emission wavelengths of samples respectively. Using Parallel Factor decomposition model, the fluorescence spectrum data matrix can be decomposed to score matrix $A$, load matrix $B$ and $C$. The decomposition model can be represented as

$$
x_{i j k}=\sum_{f=1}^{F} \alpha_{i f} b_{j f} c_{k f}+\varepsilon_{i j k}, \quad i=1,2, \ldots, I, j=1,
$$

$2, \ldots, J, k=1,2, \ldots, K$

where, $x_{i j k}$ is the fluorescence intensity of sample $i$ at excitation wavelength $j$ and emission wavelength $k, F$ is the column number of load matrix, or the number of factors, $\varepsilon_{i j k}$ is the residual element, $\alpha_{i f}, b_{j f}, c_{k f}$ are the elements in load matrix $A, B$ and $C$ respectively. The algorithm will be aborted until convergence of the PARAFAC model, that is, the minimum loss function $f_{S S R}=\sum_{i=1}^{I} \sum_{j=1}^{J} \sum_{k=1}^{K} e^{2}{ }_{i j k}<10^{-6}$.

In this study, PARAFAC modeling was performed using the MATLAB 7.0 code. The appropriate number of components was determined primarily based on the three diagnostic tools including residual analysis, core consistency and visual inspection of spectral shapes of each component, which are widely used by other similar studies. The components extracted by PARAFAC represent groups of the organic components that exhibit similar fluorescence properties. The component scores indicate the relative concentration of the groups, not the actual concentration of a particular material/fluorophore. However, it is typically assumed that the scores are proportional to the concentrations of the different components ${ }^{[5,6]}$.

\section{Fluorescence EEM Characteristics of Thiamine and Riboflavin}

\subsection{Intrinsic fluorescence EEM characteristics of riboflavin and thiamine}

For riboflavin/vitamin B2, there are three strong fluorescence areas, whose center locate at $\lambda \mathrm{ex} / \lambda_{\mathrm{em}}=270 / 525 \mathrm{~nm}, 370 / 525 \mathrm{~nm}$ and $450 / 525 \mathrm{~nm}$ respectively, and the emission wavelength ranges from about $500 \mathrm{~nm}$ to $600 \mathrm{~nm}$, as shown in figure 1 . The fluorescence intensity excited by $270 \mathrm{~nm}$ 
excitation wavelength is much stronger than that by $370 \mathrm{~nm}$ and $450 \mathrm{~nm}$, the ratio of fluorescence intensity is 1:0.41:0.25 approximately.
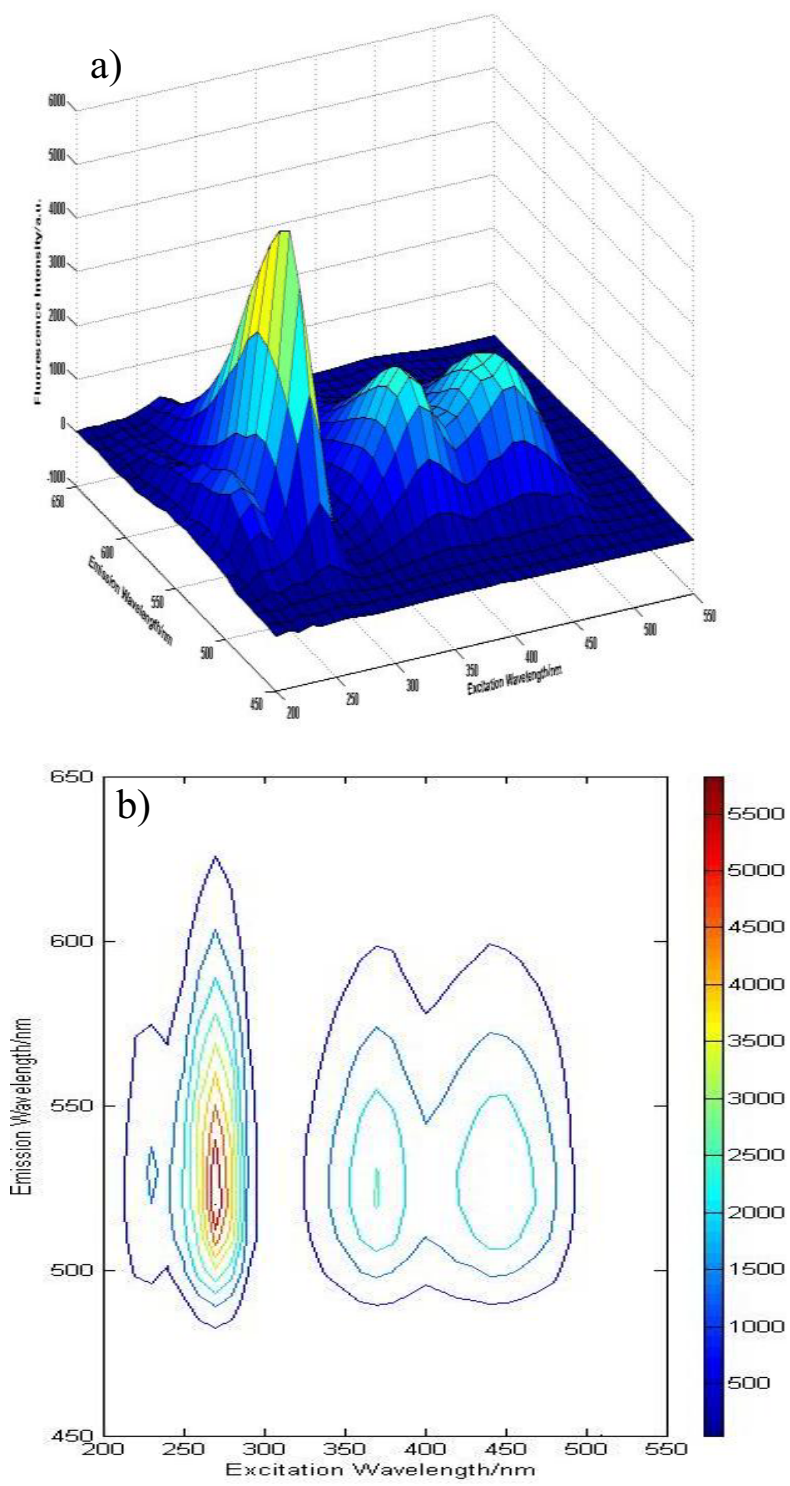

Figure 1. Fluorescence intensity distribution of riboflavin@200ug/L

Accordingly, the Thiamine/vitamin b1 has only one strong fluorescence areas, whose center locate at $\lambda \mathrm{ex} / \lambda \mathrm{em}=370 / 460 \mathrm{~nm}$, the excitation wavelength ranges from about $320 \mathrm{~nm}$ to $400 \mathrm{~nm}$, and the emission wavelength ranges from about $370 \mathrm{~nm}$ to $550 \mathrm{~nm}$, as shown in figure 2 .
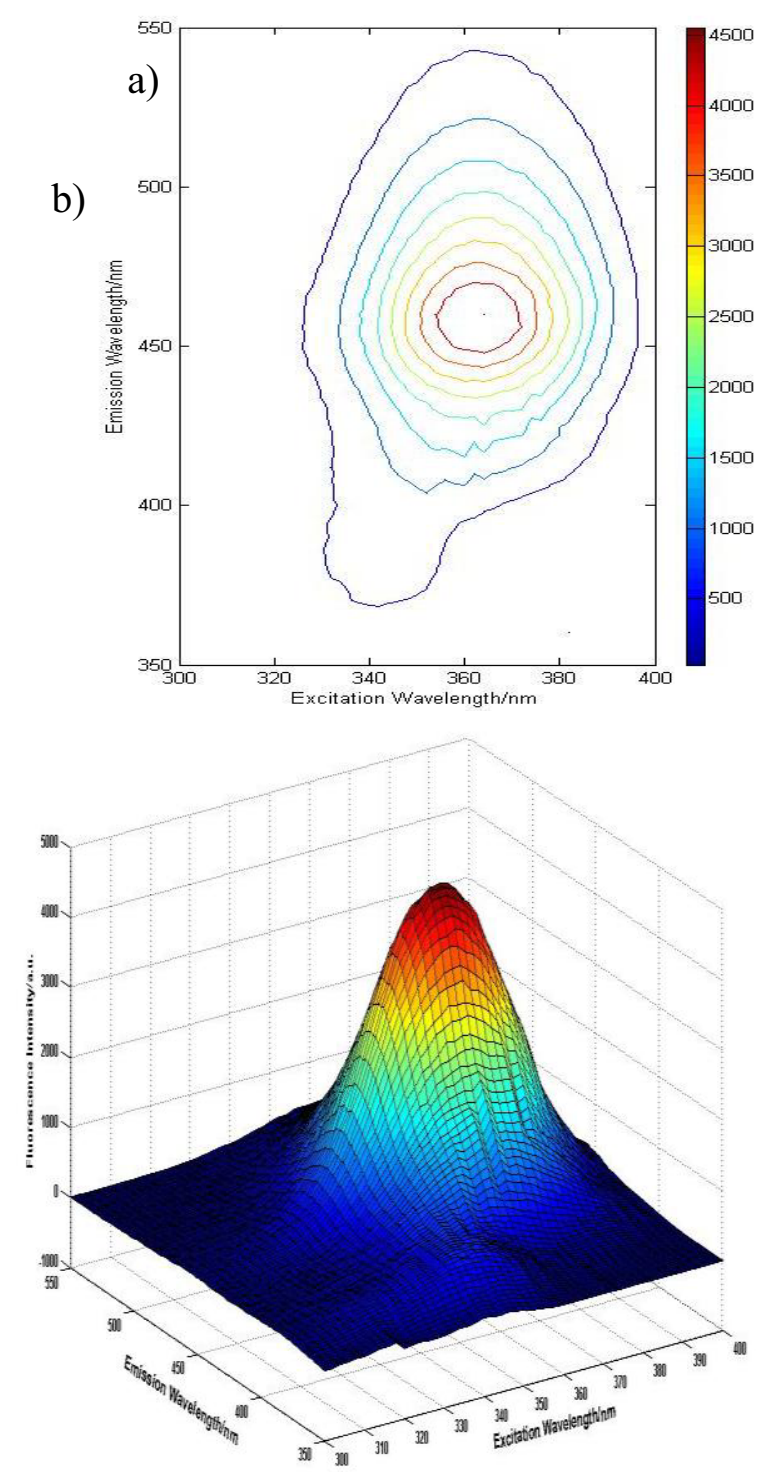

Figure 2. Fluorescence intensity distribution of thiamine@75ug/L

The fluorescence efficiency of riboflavin is about two times stronger than that of thiamine for the same solvent.

\subsection{Affection of $\mathrm{pH}$ to the fluorescence emission intensity distribution of riboflavin}



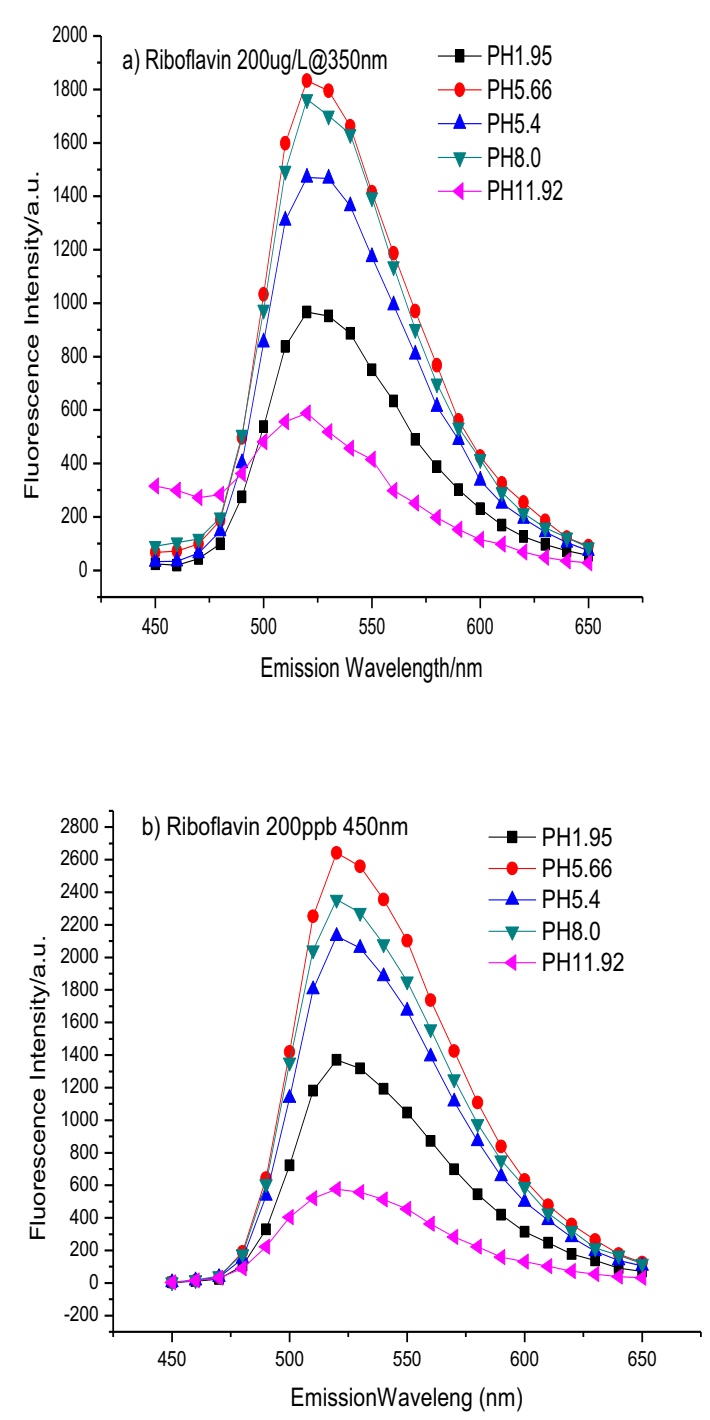

Figure 3. Fluorescence intensity distribution of riboflavin@350nm and $450 \mathrm{~nm}$ affected by $\mathrm{pH}$ value of the resolvent.

When resolved in strong alkaline and strong acid solution, the structure of vb2 molecular is distorted, so the fluorescence intensity declines sharply compared to the weak alkaline and weak acid solution, and if resolved in weak alkaline and weak acid solution, the fluorescence intensity are much stronger(figure 3).

\section{Analysis of Fluorescence Spectra of Riboflavin and Thiamine Mixed Solutions}

\subsection{Instrument settings}

Firstly thiamine and riboflavin mother liquids of different concentrations were put into $10 \mathrm{~mL}$ numbered test tubes, and then $1 \mathrm{~mL} \mathrm{Na}_{2} \mathrm{HPO}_{4}$ and $\mathrm{C}_{6} \mathrm{H}_{8} \mathrm{O}_{7} \cdot \mathrm{H}_{2} \mathrm{O}$ mixed buffer and $0.22 \mathrm{ml}$ $\mathrm{K}_{3}\left[\mathrm{Fe}(\mathrm{CN})_{6}\right]$ buffer were added into the test tubes. The $\mathrm{pHs}$ of mixed solutions were then adjusted to neutral with added $3 \mathrm{~mol} / \mathrm{L} \mathrm{H}_{2} \mathrm{SO}_{4}$ and UPW. Lastly, the mixed solutions were laid stationary for 10 minutes for the following measurements.
For the fluorescence EEM Matrixes decompose of the mixed solution of riboflavin and thiamine, the spectrophotometer excitation wavelength ranged from $300.0 \mathrm{~nm}$, to $550.0 \mathrm{~nm}$, emission wavelength ranged from $390.0 \mathrm{~nm}$ to $610.0 \mathrm{~nm}$, scan speed was set at $12000 \mathrm{~nm} / \mathrm{min}$ with excitation and emission sampling interval of $5.0 \mathrm{~nm}$, excitation and emission slit of $10.0 \mathrm{~nm}$, the PMT voltage was set at $700 \mathrm{~V}$.

\subsection{D fluorescence spectrogram of thiamine and riboflavin mixed solutions}

Fluorescence EEM intensity of thiamine and riboflavin mixed solutions of different concentrations (listed in table1) are shown in figure 4 (a) (i). The two separated fluorescence EEM peaks at $370 \mathrm{~nm} / 460 \mathrm{~nm}$ and $470 \mathrm{~nm} / 520 \mathrm{~nm}$ are obviously when the thiamine's concentration is low at $10 \mathrm{ug} / \mathrm{mL}$, and with the concentration rising of thiamine from $10 \mathrm{ug} / \mathrm{mL}$ to $25 \mathrm{ug} / \mathrm{mL}$ and $50 \mathrm{ug} / \mathrm{mL}$, the two peaks merged together.
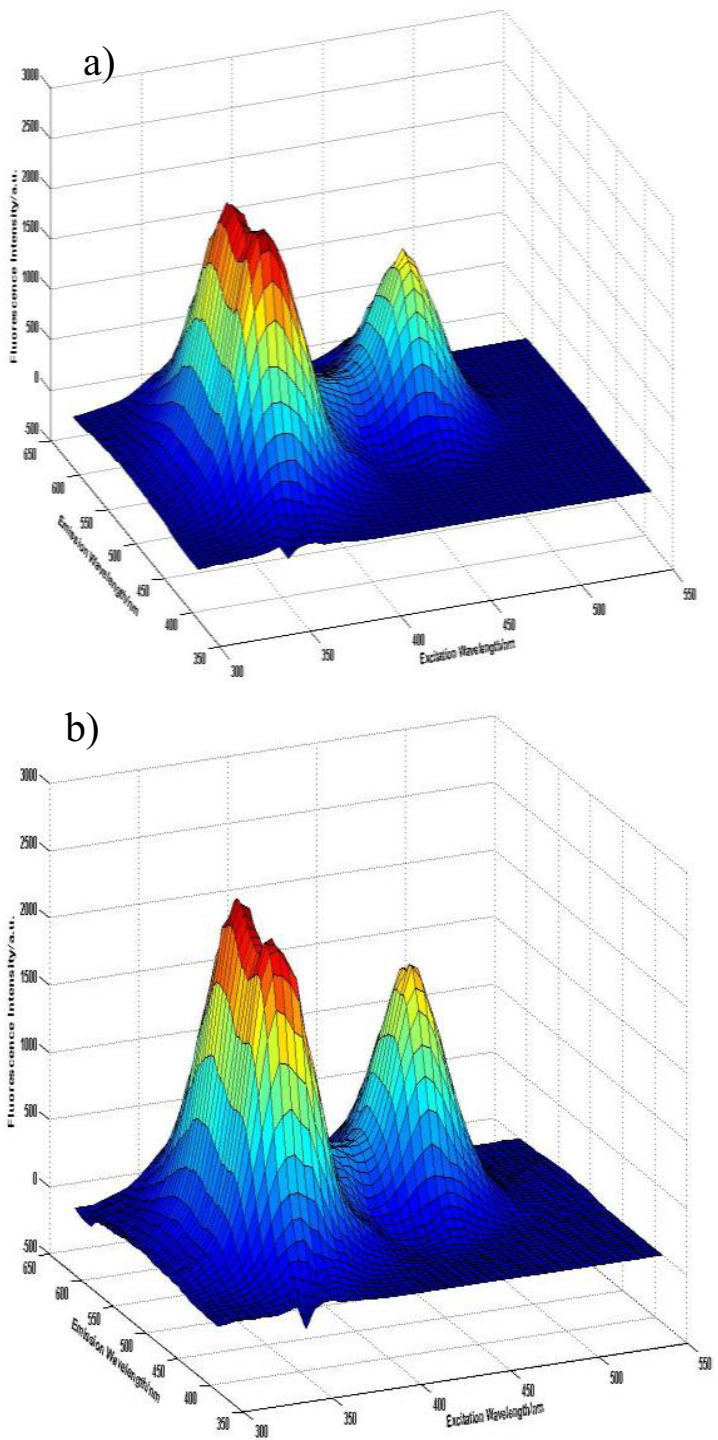
MATEC Web of Conferences 63, 03013 (2016)

DOI: $10.1051 /$ matecconf $/ 20166303013$

MMME 2016
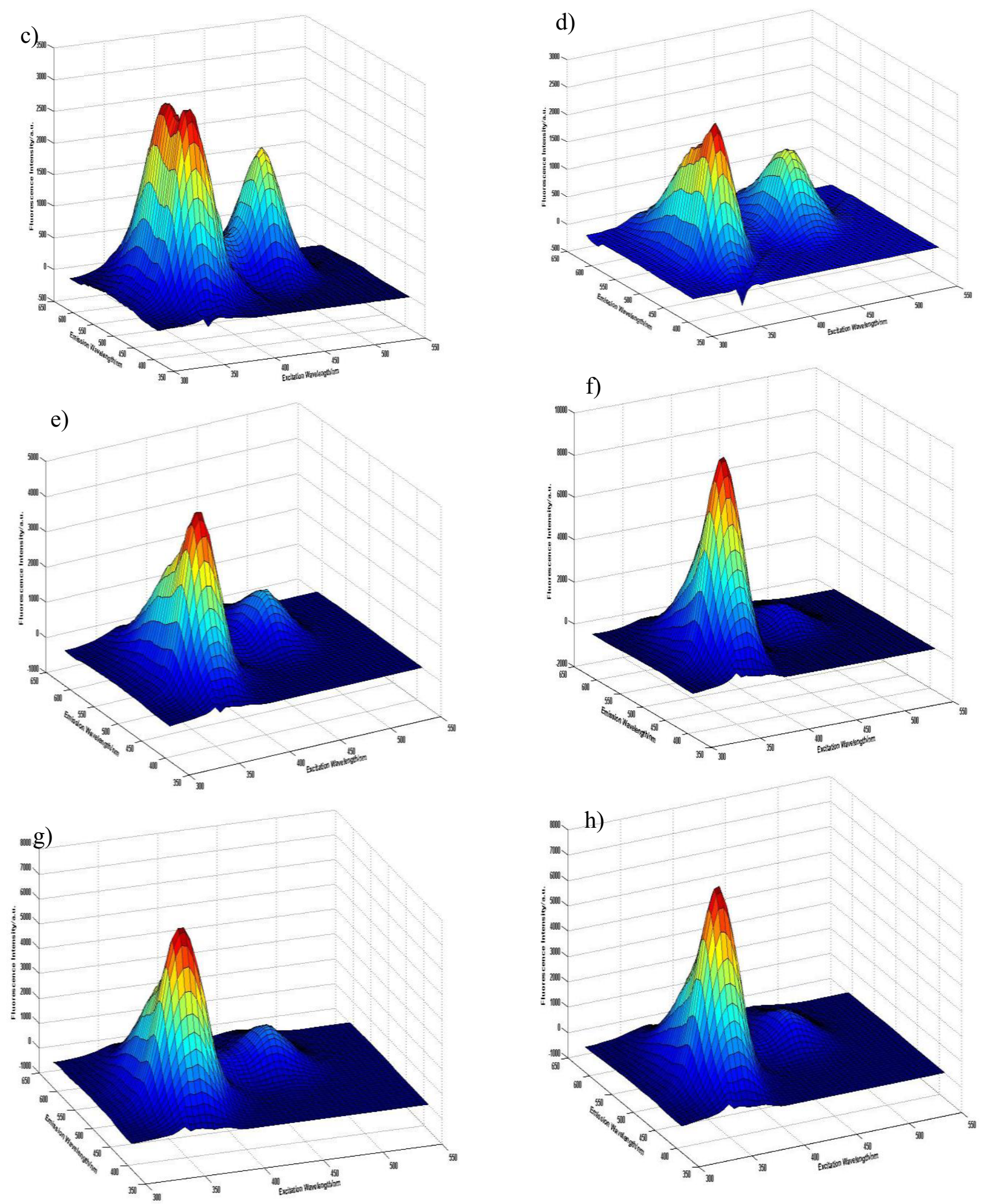

5 


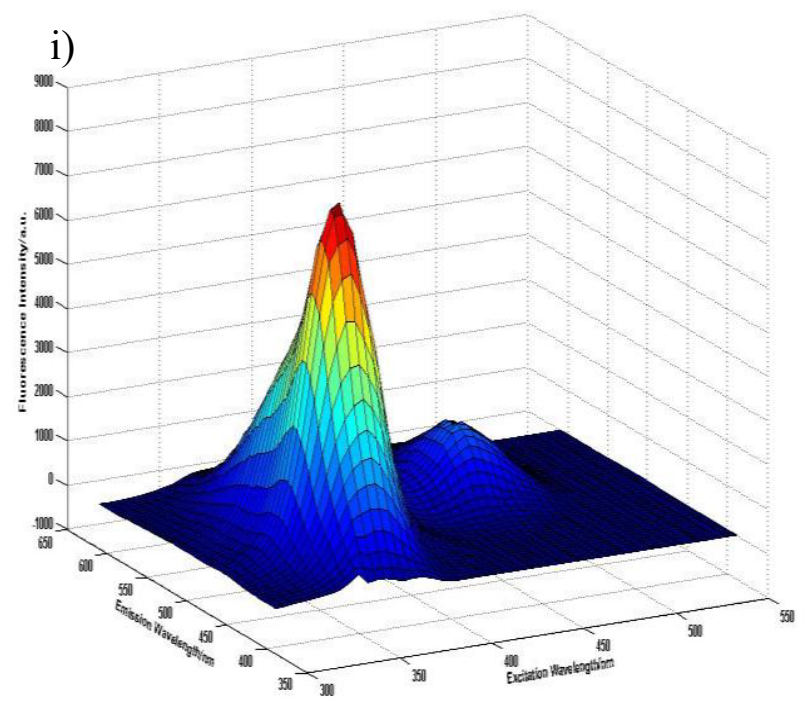

Figure 4. Fluorescence EEM intensity distribution of riboflavin and thiamine mixed solutions of different concentrations.

\subsection{Results retrieved by PARAFAC algorithm}
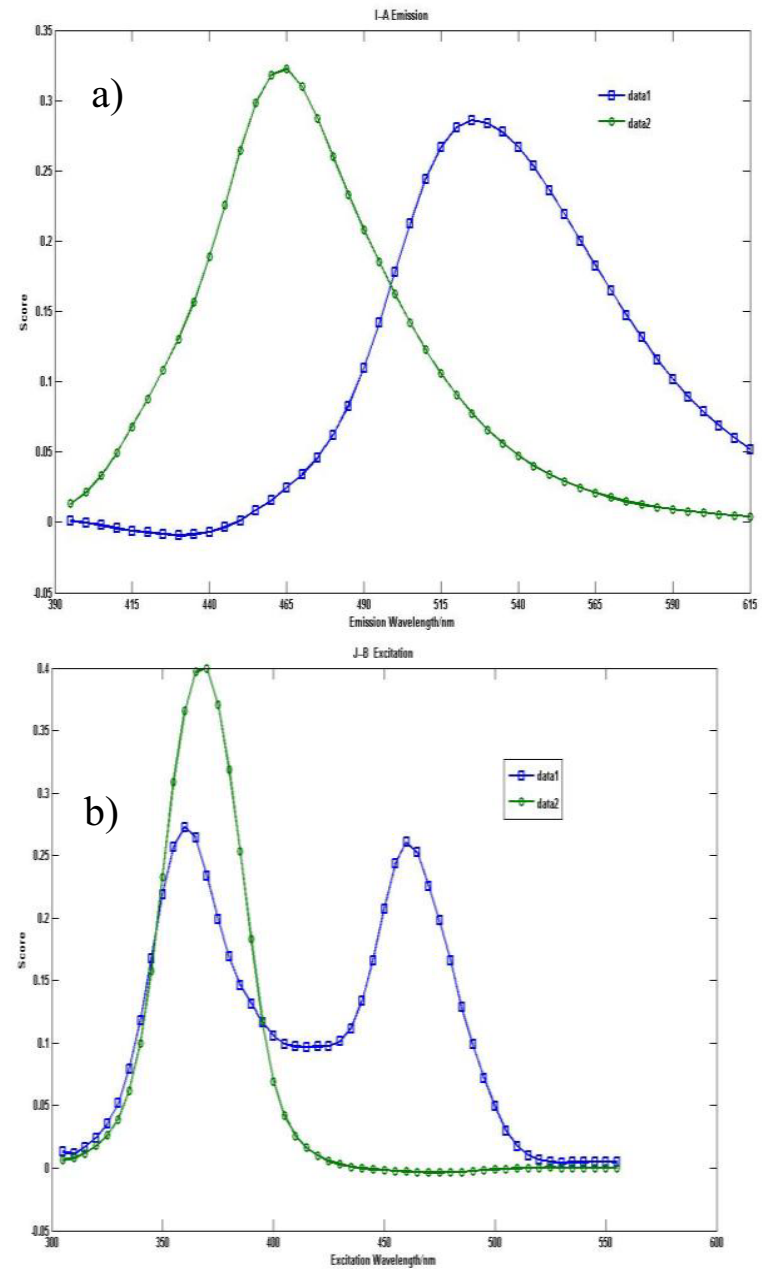
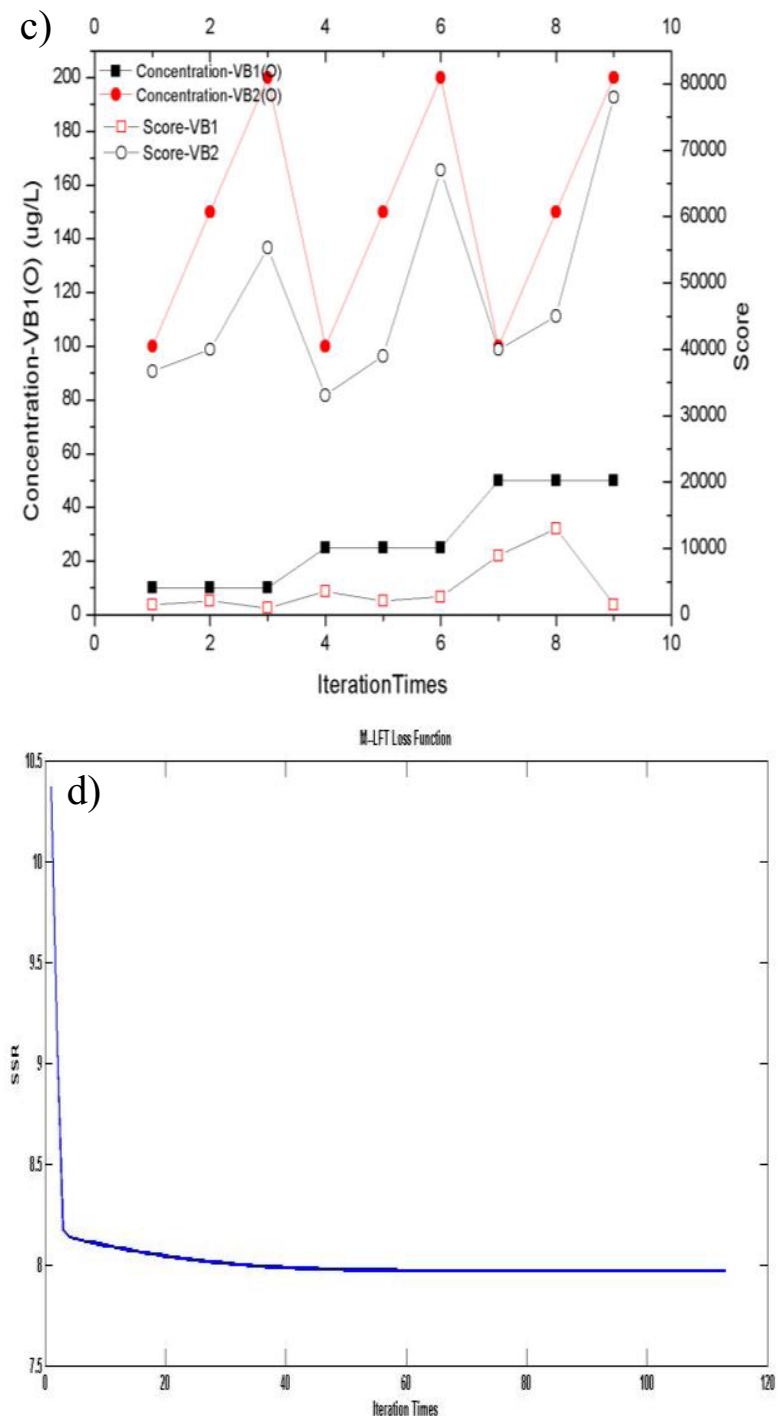

Figure 5. Excitation and emission spectral profile retrieved by PARAFAC algorithm

(a)Emission spectra, (b) Excitation spectra and (c) concentrations of original solutions and retrieved (d) SSR and iteration number

The emission spectra retrieved by PARAFAC are shown in figure 5 (a), the blue curve with block symbol (data1) indicates the retrieved emission profile of riboflavin and the green curve with circle symbol (sample2) indicates the retrieved emission profile of thiamine. From figure 5(a) and figure 1, figure 2, one can see that the retrieved emission profile and central wavelength of riboflavin and thiamine are coincident with their real emission profiles very well.

The excitation spectra retrieved by PARAFAC are show in figure 5 (b), the blue curve with block symbol (sample1) indicates the excitation profile of riboflavin and the green curve with circle symbol (sample2) indicates the excitation profile of thiamine. From figure 5 (b) and figure 1, it can be seen that the retrieved excitation profile and central wavelength of riboflavin are coincident with its real excitation profile, the two strong excitation wavelength at $370 \mathrm{~nm}$ and $450 \mathrm{~nm}$ are 
obvious. And for the retrieved excitation profile and central wavelength of thiamine, the single excitation wavelength peak is also clear and coincident with the real excitation wavelength profile.

The good linear correlations of original and retrieved concentrations of thiamine and riboflavin can be observed in figure 5(c). From figure 5 (d) one can see that SSR of PARAFAC logarithms decreases quickly and sharply at the beginning of the iteration times, the SSR is stable when iteration times $\geq 5$.

Table 1. Analytical concentrations of riboflavin and thiamine

\begin{tabular}{|c|c|c|c|c|}
\hline \multirow{3}{*}{$\begin{array}{l}\text { Samp } \\
\text { le }\end{array}$} & \multicolumn{4}{|c|}{ Component } \\
\hline & \multicolumn{2}{|c|}{ Thiamine } & \multicolumn{2}{|c|}{ Riboflavin } \\
\hline & $\begin{array}{c}\text { Original } \\
\text { (ug/L) }\end{array}$ & $\begin{array}{c}\text { Retrieved } \\
\text { score }\end{array}$ & $\begin{array}{c}\text { Original( } \\
\text { ug/L) }\end{array}$ & $\begin{array}{c}\text { Retrieved } \\
\text { score }\end{array}$ \\
\hline a) & 10 & 1500 & 100 & 36701 \\
\hline b) & 10 & 2100 & 150 & 40010 \\
\hline c) & 10 & 1000 & 200 & 55310 \\
\hline d) & 25 & 3500 & 100 & 33090 \\
\hline e) & 25 & 2100 & 150 & 39010 \\
\hline f) & 25 & 2700 & 200 & 67001 \\
\hline g) & 50 & 8900 & 100 & 40010 \\
\hline h) & 50 & 13000 & 150 & 45010 \\
\hline i) & 50 & 1520 & 200 & 78001 \\
\hline
\end{tabular}

\section{Conclusions}

The fluorescence of a protein or bio-aerosol or bio-agent is a mixture of the fluorescence from individual aromatic residues and coenzyme. Using fluorescence Spectrophotometer, the intrinsic fluorescent characteristics of vitamin $\mathrm{B} 1$ and vitamin $\mathrm{B} 2$ are measured with solutions of different $\mathrm{pH}$ and discussed. Vitamin $\mathrm{B} 2$ and vitamin $\mathrm{B} 1$ mixed solutions are successfully decomposed and resolved by PARAFAC algorithm. The retrieved emission profiles, excitation profiles, central wavelengths and the concentration of the two components are coincident precisely with real emission profiles, excitation profiles, central wavelength of each component.

\section{Acknowledgments}

The work was supported by the National Natural Science Foundation of China named "Study on Technology of Ultraviolet Laser-induced Fluorescence LIDAR for Bioagent Remote Sensing" No. 41375026.

\section{References}

1. National Academy of Sciences, 2004. Sensor Systems for Biological Agent Attacks: Protecting Buildings and Military Bases, Committee on Materials and Manufacturing Processes for Advanced Sensors, Board on Manufacturing and Engineering Design, Division on Engineering and Physical Sciences, National Academies
Press Washington URL: http://www.nationalacademies.edu/bmed [Accessed: Jan. 23, 2015].

2. Stedmon, C.A.; Markager, S.; Bro, R. Tracing dissolved organic matter in aquatic environments using a new approach to fluorescence spectroscopy. Mar. Chem., vol 82, pp 239-254, Aug. 2003

3. Murphy, K.R.; Hambly, A.; Singh, S.; Henderson, R.K.; Baker, A.; Stuetz, R.; Khan, S.J. Organic matter fluorescence in municipal water recycling schemes: Toward a unified PARAFAC model. Environ. Sci. Technol., vol 45, pp, 2909-2916. Mar. 2011

4. Stedmon, C.A.; Bro, R. Characterizing dissolved organic matter fluorescence with parallel factor analysis: A tutorial. Limnol. Oceanogr. Methods, vol 6, pp 572-579, Nov. 2008.

5. Ni Yong-nian, Cai Ying-jun, Simultaneous synchronous spectrofluorimetric determination of vitamin B1,B2 and B6 by PARAFAC, Spetroscopy and Spectral Analysis, vol 25, no. 10, pp 1641-1644, Oct. 2005

6. Li Weihua.; Sheng, G.aoping.; Liu, Xianwei.; Yu H.anqing. Characterizing the extracellular and intracellular fluorescent products of activated sludge in a sequencing batch reactor. Water Res, vol 42, pp, 3173-3181, Mar. 2008. 